\title{
General Physical-Geographical Characteristics of Çermenike, Golloborde, Martanesh Highlands
}

\author{
Msc. Elvira Bollobani (Dodoveci)
}

elvirabollobani@yahoo.com

Doi:10.5901/ajis.2013.v2n3p343

\begin{abstract}
In this paper are treated some general physical - geographical characteristics of Çermenike - Golloborde - Martanesh highlands, which mainly lie in the central and eastern part. The work is focused on the geological and litological construction of the studying zone. The article makes effort to analyze the morphotectonic and morphoclimatic evolution of the relieve in these high-lands. For the realization of this work are utilized the main works and so far editions about this thematic and are contacted the corresponding area specialists.
\end{abstract}

Keywords: geologic construction, litologic construction, morphotectonic evolution, morphoclimatic evolution.

\section{Introduction}

In the geographic context of this area morphological and morphotectonic boundaries stand out with other restrictive units such as: mountain range of Lura in the North, upper stream valley of the Shkumbin river in the South, Black Drini valley from east and North - East, whilst in the West the mountain range of Skanderbeg up to the upper valley of the Ishem river. The general shape of an irregular quadrilateral is expressed significantly in the length nearly East (the mountain of Raduc) - West (the mountain of Kesula) about $38 \mathrm{~km}$, whilst the width from the North (Zalli Bulqiza), in the South (Qarrishte) nearly $30 \mathrm{~km}$. Greater heights of this area lie in Golloborda to the mountain of Kallkan $(2132 \mathrm{~m})$ the mountain of Raduc (2081 m), Martanesh and the mountain of Dhoks (2020 m) the Big Snoi (1848 m), whilst the mountain of Çermenika is distinguished by a hilly - mountain relieve due to the prevalence of the terrigenous rocks. ${ }^{1}$

To a morphological importance it is simultaneously presented the extension of the erosion basic level almost the eastern outskirts (Black Drini), North-West (the Mat river), western (the Erzen river) southern (the Shkumbin river) which have as a watershed the relieve of this area. Regarding the changes of the heights expressed, which characterise the relieve's shapes of the area, we emphasize that they are explained with the values of different tectonic elevations of the structures where they have been modeled (Aliaj 2012).

Geographical extension of these alps and the height above the sea level have also defined the conditions of mountainous eastern mediterranean climate with a harsh and wet, winter the rainfall mainly fall in the snow shape thanks to the frost presence during this season. This area is distinguished by a relatively wide aperture toward North - West and South - East through the course of the upper valley of the Mat and Shkumbin river. In the North - East and South - West direction are created links respectively through the valley of the upper stream of Black Drini and Shkumbini being in a crossroad movement of different air masses with influences expressed in its climate. The apperture of those highlands toward North - East and South - East have created appropriate conditions for cold and dry air masses insights, while from the North - West and West, wet air masses are insighted, especially in the western half of them, where simultaneously are found the greatest heights. These features of climatic conditions have a direct influence in the distribution of water resources of this area in which the greatest quantity of the water flows during its western part, ending to the Mat, Erzen, Shkumbin river.

The greatest water resources are found in the carbonate massif of Martanesh Vali and that of the Martanesh highland, which are linked to the dense development of its chartogenecis. (Gruda 1996). This water network with the big values of its density constitutes outter relieve forming phenomenon, leading to the modeling of the genetic complex of the relevant relieve. This type of relieve has a large extension, which is immediately ranked after that structural,

${ }^{1}$ Group of authors (1991). Physic Geography of Albania. Volume II, published by Academy of Sciences PRA, Tirana. 
simultaneously being presented with a morphological evolution relatively fast, especially in the territories built by terrigenous rocks (Gruda et al. 1997). The other side this water network encourages also other relieve forming phenomenon activities, especially carstogenesis and slopes phenomenon, because it constitutes the basic level of their erosion (Kabo 2005). With a great importance simultaneously are presented the valleys, gorges and coves formed by this water network, because they create appropriate conditions for the connection of these highlands, adding to the presence of multiple necks with an extremely different height.

Between the most important gorges, it is separated Vali's gorge, between the Mati, Erzen and Shkumbin valley. Llenga's gorge, between Shkumbin and Black Drini valley, whilst the most important necks are: Rinas's neck between Erzen and Shkumbin, and that of Prevalle, where the connection east - west among these highlands is made.

\section{Geologic Construction of the Area}

Physical - geographical boundaries of these highlands are included in two tectonic areas that of Mirdita, which occupies the majority and that of Krasta with a characteristic position of a tectonic nedging (Aliaj 2012). With an emphasized change from other physical - geographical units of our country, these highlands are characterised by a very complicated litologic and structural construction, which is directly linked to a powerful tectonization not only between different types of rocks but simultaneously within the same type. These morphostructural features are conditioned by morphotectonic and tectodynamic evolution with characteristic features, which are expressed extremely good even in their situation nowadays. The morphotectonic framework of these highlands is extremely complicated by the wedging of the structure of the flysch cretaceous Paleocene in a direction almost tranverse of Mirdita area, representing a tectonic window of Krasta - Cukali area. ${ }^{2}$

This area lies also in the West of these highlands, among a covering carbonatic structure of the Gropa mountain in North - West and ultrabasic massive of Kuterman from South, constructing a reservoir of the upper stream of the Erzen river. Over these morphotectonic conditions, the flysch structures of Krasta area interrupts transversely the general dinaric direction (North - West and South - East) of the carbonatic, magmatic and flyschoid structure extension of Mirdita area. On the whole flysch rocks and those flyschoidale stretch almost the central part of this area, especially in Golloborde and Çermenike, whilst those limestones and magmatic in North - West and South, of which Martanesh and Golloborda's highlands are the most distinguished (Melo 1982).

The structuring of these rocks is done by some tectodynamic phases, which are expressed in the presence of deformations and those dissociative, with a morphological importance presented in our todays relieve of these highlands. Of course, the crucial role of the relieve of this area is thanks to the second stage of the evolution of the morphotectonic Albanides, which has led into the formation of morphologic subunits of these highlands. (Shallo et al. 1980). According to the morphogenic importance of the geologic construction of this area, in continuance to the litologic, tectonic construction, new tectodynamic conditions and today's morphologic evolution of these highlands will be treated.

\section{Litologic Construction}

The diversity of the rocks of these highlands as it is emphasized above, dominate the limestones, which build almost the whole tectonic area of Mirdita. ${ }^{3}$ The wider stretch is on the half West of Martanesh, where the limestones the covering structure among the upper valley of Mat and Lugu of Valit (Gruda 1996). From the East limestones build the greatest part of Golloborda in the shape of a massive among Trebisht in the North and Stebleva in the South, whilst in the South East they reach up to Lunik and Qarrishte combined with flyschoid (Papa 1987).

They represent the oldest rocks of these highlands with a triasic age which are constituted by silicious limestones, dolomites and limestones which build the highest shapes of the relieve, adding simultaneously the dense rate of their tectonic fragmentation. The heights of the relieve's shapes built by these rocks, especially Raduc mountain (2081 m), Miraka mountain (1998 m), Big Snoi mountain (1846 m), ect, are linked to the amplitude of the new tectonic increasing. Exactly over these rocks aside from the structuring relieve, there is developed that carstic between the carstogenic phenomenon (Krutaj 2006).

Similar to limestones are those terrigenous, which are represented by flyschoids and flyschous with different

2 Group of Authors. (1983). Geologic map of Albania and the explanatory book Geology of Albania, Tirana.

${ }^{3}$ Group of Authors. (1983). Geologic map of Albania and the explanatory book Geology of Albania, Tirana. 
litologic composition but with a similar stretch direction, NE - SW. Flyschous rocks are made of alevrolits, marls, sandys and calcareous marls, conglomerate and interracial ophiolite and silicious limestone (Melo 1982). This litologic composition of these rocks has influenced the selective erosion phenomenon in the modeling of the landscape of these highlands, leading to the creation of the emphasized morphological contrasts. The dominant shapes of the relieve over these rocks are mainly valleys, coves, which are separated by eroded ridges where huge values of the fragmentation density and those mainly of an average depth fragmentation of this relieve prevail. It is also important to emphasize that the heights up to 1800 - $2000 \mathrm{~m}$ above these rocks, especially those flyschoids are directy linked to their rising tectonic amplitude such as the top of Raduc (2081 m), Kaptina (1851 m), Kalkan (2132 m), ect.

A morphological importance presents also the dense combination of flysche of Krastes with secondary an anticline structures of the cretaceous limestone, which lie entirely in the upper stream valley of the Erzen river, with a length of 6 $18 \mathrm{~km}$ and width of $4-13 \mathrm{~km}$. Under these morphostructural selective erosion conditions especially that of water leakage, has scoured clays and marls, creating an unstable situation for sandys and limestones to which they are combined. The expansion almost the center of both highlands and rocks are exploited by the water network of the Okshtun stream, which has created the valley with the same name among mountain blocks of Vali's hoks and Martanesh in the North - West and those of Golloborda in the South - East of this valley. This flysch position has simultaneously influenced in the tectonic direction over this morphological phenomenon (Kabo 2005).

In the lithological composition of these highlands a considerable expansion occupy even those magmatic ultrabasic, which are represented by the massive of Bulqiza (Dhoksi) which builds up the eastern part of Martanesh, whilst in the South - West of Çermenika the massive of Kuterman (Uloku) with a very small size. ${ }^{4}$ In general these rocks, as those limestones, are extremely sustainable over outer morphogenic phenomenon, especially the water leakage despite the dense rate of the tectonic fragmentation.

It is especially distinguished the massif of Bulqiza, which is tectonically extended among the eastern and western band of the Triassic limestones, creating the conditions for a powerful destruction with a morphological importance. Naturally it is emphasized the lowest rate of these rocks, despite their dense cracking which is presented in the relieve with high values of density of its fragmentation (Gruda 2011).

The resistance sustainability of these rocks toward erosion, has simultaneously defined high values of the depth of this fragmentation, conditioning, also emphasized morphological contrasts, which are directly connected with the amplitude of their increasing tectonic structure. The massive shape of these rocks is connected not only to their origin but simultaneously with the new blocking tectonic, being well reflected in the relieve by maintaining the fragmented shape of the erosional neogenic surface, similar to other ultrabasic massives of the place (Aliaj 2012).

Under these topographic conditions the height expansion and the poor permeability of the ultrabasic rocks, traces of the morphogenic quaternary glacial are connected and expressed by the circus presence, especially among the northern and eastern slope of the Dhoksi mountain. The change of the strength of these rocks and of those limestones in accordance to those terrigenous mentioned above, despite the different amplitude of their tectonic increasing structures, explains the emphasized morphological contrasts of the landscape of these highlands with visible alpine features.

\section{The Area's Tectonic}

In the framework of the tectonic area, there are also presented the diverse shapes of the deformation of the terrigenous, carbonatic, magmatic structures. The structural complex of these highlands as part of those of the Albanaids in the whole, is directly connected to the morphotectonic evolution in some phases. The dominant tectonic regime of the first phase led to the ruffle formation and disconnections until the covering, including even the tectonic "window" of Okshtun (Saint Georges holl) (Qiriazi 2006). During the second phase the tectonic regime with a differentiated feature and normal disconnection has given a blocking shape expressed to all above mentioned structures (Shallo et al. 1980).

The cause of this tectodynamic phenomenon are the morphological features less expressed to the ruffle structures, thank to their complication because of different tectonic detachment. Among the longitudinal disconnections, show up Mirdita between the tectonic area which is represented by the limestones, Mesozoic flyschoids, above flysches and cretaceous - Paleocene of Krasta's area in the West. ${ }^{5} \mathrm{New}$ tectoorogenesis, especially secondary quaternary till nowadays, have simultaneously conditioned the height changes among mountain ridges during their expansion, reflecting

${ }^{4}$ Group of Authors. (1983). Geologic map of Albania and the explanatory book Geology of Albania, Tirana.

${ }^{5}$ Group of Authors. (1983). Geologic map of Albania and the explanatory book Geology of Albania, Tirana. 
directly in compliance of the relieve with the structure and lithology. On the relieve of this area in whole oven to that structural in particular have influenced also tranverse tectonic dissociations, which the great part of the cases constitutes morphotectonic loundaries of its morphological units (Gruda 2003). Among them show up from the size and morphogenic importance the tranverse disconnection Vlora - Elbasan - Diber which interrupts diagonally the structures of these highlands being almost aligned with the tectonic "window" of Saint George (Okshtun) (Gruda 1996).

On expansion this disconnection has undergone tectonic differentiations being reflected in the formation of two graben structures outside the study area, that of the pond of Dibra in the North - East and the hollow of Elbasan from South - West which constitute simultaneously the basic level of the erosion of this area. This disconnection divides almost the structures completely terrigenes and limestone in the South - East from those mainly magmatic and limestone from its North - East while maintaining simultaneously the tranverse direction of their expansion. Among the main shapes of the relieve modeled during this disconnection in this area are tectonic cove of Okshtun and the slope steep of the mountain range defined to the same origin. Parallel to this tranverse are also tectonic connections during the terrigene rocks contact to those carbonatic and magmatic in its North - West and South - East which in the relieve are expressed with clear tectonic steeps (Gruda 1996).

Atranverse tectonic disconnection with special morphological importance there is also submitted that of Bulqiza's sand which lies from East - West, being interrupted by that of Lushnja - Dibra and Black Drini exactly to the grab plinth of the pond of Dibra. This disconnection interrupts the ultrabasic massif of Bulqiza (Dhoksi) in the South, from that of Balgjai in the North, in which are formed two mountain blocks with the same name, constituting simultaneously, as it is mentioned above the morphotectonic and morphologic boundary of this area with the mountain ranges of Lura in its North. Evidence of a morphogenic importance and sizes of these tranversing are expressed to the sizes of the valley with the same name, especially between Bulqiza and Valikardha. In the limestone terrigene and magmatic structures of these highlands are met a series of tranverse longitudinal secondary disconnections, which have a visible influence in morphogenesis especially, in the complex of the structural relieve.

Of course the decisive importance in the formation and relieve evolution of this area, as everywhere in our country are the new tectodynamic conditions and those of today's which have included all its structures. Almost all the structures mentioned above of these highlands are involved by tectonic increased with a value of over $1000 \mathrm{~m}$ of all their morphotectonic evolution period, expressed directly in the mountainous relieve development even nowadays, especially in the terrigene rocks (Aliaj 2012).

\section{Morphotectonic and Morphoclimatic Evolution of the Relieve}

The current morphologic framework of these highlands' surface, like all the surface of the country in general, starts with a new tectonic deformation of the neogenic peneplene structural basis, which is displayed in fragmental shapes and different altitudes, due to its differentiating nature. This tectodynamic phenomenon variably increases its values until it reaches the peak in middle quaternar, defining in the same time the increasing of the size of morphological units comprising these highlands, which have been modeled along its structures. The period of the morphotectonic Pliocene quaternary evolution of this zone is evidenced instantly by the molasic lake deposits of this period, which end at in the North - East edge among Sopot, Cerenec and at the graben basin pond of Dibra.

It should be emphasized that during this period were also formed the morphotectonic and morphologic boundaries of the main subunits of today's surface, because the new tectonics have also renovated the previous structures making them quite active in their development (Aliaj 2012). The development of exterior morphological activity, especially that of aquatic outflow, has been triggered mainly by new tectonic elevations, whereas the climatic conditions have influenced firstly along the quaternion with their dense frequent changes, especially during glacial periods (Krutaj and Qiriazi 1987).

The traces of this activity, accompanied simultaneously with that of frosts, are well retained in the nowadays surface, especially in the mountains of Dhoks, Kallkan and Raduc. Due to the predominance of river networks in the exterior morphological phenomena, in the relieve evolution, of course that the interrelation of this network with the structures of the zone is of special importance, during the whole period of this evolution. The antecedent type of this network is related to the continuous tectonic elevation of the structures which it intersects, whereas the presence of tectonic disjunctions near or along the track, has simultaneously determined the complex character of the tranverse cross river gorges, especially those of Val, Borova, Kuterman, and the biggest one, that of "Zalli Bulqizes". (Meçaj and Kuçana 2006).

The depth of these gorges not only evidences the amplitude of these new tectonic elevations, but also proves that the erosive activities of the aquatic gorges, which they have formed, have managed to with stand the rates of these 
elevations during the whole period of their modeling. During Holocene period, immediately after the melt of debacle of Vyrm ices, the morphologic development of this relieve is led by aquatic outflows, by-accompanying slopes phenomenas, frosts, avalanches, waters of melted snow and carstogenic waters in the calcareous massives.

The almost complete domination of the mountainous relieve has determined, also, intensive snowfalls and a relatively long period of frost, which play a morphologic role manifested in the development of this relieve. Along the slopes with high altitude and inclination, such as the mountainous block of Dhoks, Val of Martanesh, Kallkan, Raduc etc., avalanches have formed their traces, along which concentrated rinse-outs are developed during the period when snow melts, or heavy rainfalls in autumn.

This slope phenomenon has led to the formation of a dense network of streams, and tributaries along the terrigene and magmatic territories, which play a significant role in the development of the relieve, especially in its degradation. Among them, it is worth mention the dense network of derivations in the Rrapuni Stream, that in the upper outflow of Erzen river and along the Okshtuni stream, which are developed in most of its parts in the terrigiene cliffs. The density and surface of the extension of these phenomena, of course, are directly related to the extent of beds deepening in the above mentioned outflows, which increase the inclination of slopes and their width (Qiriazi 2006).

Frosts are most densely developed in the mountainous block of Dhoks, Miraka, Kallkan, Raduc, Valit of Martanesh, Lunik mountain, being evidenced by the presence of powerful coluvo-proluvial cones at the foot of these mountains. It should be emphasized that these slope phenomenas, are closely connected with rinse-outs, which is manifested by the fact that they meet in the territories where the latter have been developed, especially along the surface of Rrapun Ezen and Okshtun draws. The approach of the above mentioned morphotectonic and morphoclimatic evolution of the relieve of this area testifies that the cyclic character of its development is led by fitfull activity and pronounced differentiating nature of the new tectonics, triggered simultaneously by the frequent climatic changes. A good knowledge of the development of this relieve is achieved by means of studying the morphologic and morphogenic traits in its entire current complexity.

\section{Morphologic and Morphogenic Particularities of the Area}

The morphologic complex of this area is presented quite variable and complicated, although it is separated by the morphotectonic and morphologic boundaries expressed with other limitative zones.

In the general framework, its relieve is characterized by an almost regular interwinement of mountainous ridges in the form of strings, of a block or highland. The mountainous character of these highlands is manifested in the prevalence (87\%) of altitudes above $900-1000 \mathrm{~m}$, whereas the hilly one with an altitude of $500-800 \mathrm{~m}$ lies in the form of a narrow band at their North - East and South - West edge. ${ }^{6}$ This is exactly the main orientation of the expansion of mountainous ridges, which is directly connected to the lowest rates of erosion basic level, namely, from North - East of the Black Drini river, and South - West of the Shkumbin river. The high density rate of relieve friction is typical of sections with terrigene components, namely, along the draws of Okshtun stream, Rrapun stream, and Erzen stream, with the dense network of outflows, the rates of which reach $3-6 \mathrm{~km} / \mathrm{km}^{2}$. In these sections are created degraded surfaces with numerous erosion hearths, among which almost the entire section of Rrapun Draw shows up, especially in the villages of Bena, Ballgjin, Neck Qerret, Kostenja, Pervalla, Funara, etc. With similar rates of friction, the upper section of Okshtun flow manifests itself, especially in the villages of Prodan, Small of Okshtuni, Ternove, Smollik, etc., which trigger sloppy phenomena and risk the destruction of the agricultural land. Whereas along the draw of the upper flow of the Erzen river, are distinguished degraded surfaces in the villages of Verri, Big Shengjin, Faceshi Bridge, etc.

On the whole all the high rate of relieve friction is met, also, in the section costruted by ultrabasic cliffs, especially to Bulqiza's massif along the tectonic scarp of the North and West slope of the Dhoks mountainous block. Its friction rates reach $3-5 \mathrm{~km} / \mathrm{km}^{2}$, which, triggered by numerous tectonic disconnections exploited by this aquatic network. The morphological consequences of this friction are the numerous erosion hearths in the drawned surfaces of the above mentioned scarps, which are accompanied by sloppy phenomena in the villages of Valikardhe, Zerqan, Sopot, Strikcan, etc. In accordance to the low rates of friction density $\left(0.3-0.9 \mathrm{~km} / \mathrm{km}^{2}\right)$, it should be emphasized that they are typical of the carstic relieve of Val of Martanesh, and the mountainous ridge, of Lunik, up to Trebisht, in which superficial flows are completely absent. Regressive erosion and continuous deepening of aquatic flows are a reflection in morphogenesis of these tectodynamic conditions, leading to the creation of numerous above mentioned outfalls.

The highest rates of this friction belong to tectonic scarps of limitary slopes in North, West, South - West of Dhoks 
mountain, Val of Martanesh, that South - East of Lunik, that South of Mirak etc. Whereas the most typical outfalls in the form of canyon are those in the carbonatic mass, such as that of Mat up to Vasha Bridge, Valit and Borova, which have the morphologic typical features of canyons with a depth of $300-500 \mathrm{~m} / \mathrm{km}^{2}$ (Aliaj 2012).

Differently from them, the low rates $\left(50-100 \mathrm{~m} / \mathrm{km}^{2}\right)$ up to average rates $\left(100-300 \mathrm{~m} / \mathrm{km}^{2}\right)$ the relieve friction depth in this area lay generally in the sections constructed by terrygene cliffs, in the most parts of highlands of Cermenike and Golloborde. In particular the low rates of this friction especially lay in the above sections of aquatic flows, including territories of settlements such as stream of Kostenja, Pervalla, Gurakuq, Rinas, Lugaxhi, Ternova, Thekna, Lena, etc., in settlements with the same name.

Another morphologic phenomenona of the relieve of this area, is also, the exposition of slopes, which is directly connected to the rates of density, depth and the direction of its friction. The prevailing orientation of friction, as treated above, is NW - SE and NE - SW, determining in the simultaneously such an exposition of the slopes. Along these orientations, slopes with almost eastern and western exposition also meet, which are typical of boundary slopes the Mountain of Gropa, Val of Martanesh, Dhoks, mountain, Kuterman mountain, etc., adding simultaneously almost northern and southern exposition of these mountains. By the analysis of the relieve friction rate, especially that of the depth of this friction, in which average and high rates prevail, its convulsive morphotectonic and morphologic are clearly presented even nowadays. The coignition of this morphological activity presents simultaneously a special practical importance, which serves to take preventive measures against some risks of relieve-forming phenomena, especially to preserve the agricultural land, residential lands and infrastructure in general.

\section{Conclusions}

The position and the dimensions of this area, have also determined, the special physical-geographical importance, with great natural resources, which are related to geographical position, lied in two tectonic areas. They have conditioned a diversity of cliffs and folding and fractioning structures, with different dimensions, which are expressed in morphologic complexes, typical of the relieve. Not only the diversity of the cliffs, but also their position over these highlands manifest themselves with high morphological importance. in the lithological composition the magmatic and ultrabasic ones are distinguished noting, which are represented by the Bulqiza (Dhoks) massif, in which sources of chrome mineral are located, which are exploited by private subjects, whereas in the SW of Cermenik the massif of Kuterman (Ulok) is included, with much smoller dimensions.

The above mentioned natural conditions above mentioned are quite suitable, also, for landslides and collapses, which encompass a wide area in the terrigene cliffs, especially the last, whereas collapses are mainly met during the tectonic contact with calcareous and magmatic ones. The cognition of this morphological activity presents simultaneously a special practical importance, which serves to take preventive measures against some risks of relieve-forming phenomena, especially for preserving the agricultural land, residential lands and infrastructure in general. Based on morphological characteristics, morphologenic and morphostructural factors of this area in its different sections, which were treated in general above, its worth mentioning, some morphological units, such as the highlands of Cermenika, Golloborda and Martanesh. This division has a mainly oriented character, since in general they have a natural connection between them, forming a mountainous block where the aquatic division between the three most important rivers of our country, such as Black Drin river in the North - East, Mati river in the North - West, and Erzen river in the South - East, where as Shkumbin river on Souths, done.

\section{References}

Aliaj, Sh. (2012). Neotectonics of Albania, Monography, Tirana.

Group of authors (1991). Physic Geography of Albania. Volume II, a publishement of Academy of Sciences PRA, Tirana.

Group of Authors. (1983). Geologic map of Albania and the explanatory book Geology of Albania, Tirana.

Gruda, Gj. (2003). Geomorphology, Monography, Tirana.

Gruda, Gj. "Evaluation of natural and human potential in the sustainable development of martanesh commune", in: Albanologic Studies, No.4/2011, Tirana.

Gruda, Gj. "Morphologic picularities of crasps and tectonic fractions in Albania in: Geographic Studies, No. 8/1996, Tirana

Gruda, Gj. Sala, S, \& Ziu, T. "Quaternary ice in Albania and its role in relieve", in: Geographic Studies, No. 2/1987, Tirana

Kabo, M. "Morphologic piculatiries of Albania and their role in the hydrographic network", in: Geographic Studies, No. 15/2005, Tirana

Krutaj, F. \& Qiriazi, P. "Current exterior processes that model the relieve of our country", in: Geographic Studies, No. 2/1987, Tirana.

Krutaj, F. "Some picularities of Golloborda carst", in: Geographic Studies, No. 17/2006, Tirana.

Meçaj, N., Kuçana, M. "Some geomorphologic picularities of the river valleys", in: Geographic Studies, No. 17/2006, Tirana. 
Melo, V. "Flish distribution in flish language in Peshkopi - Labinot and opinions related to its paleogeographic and tectonic location", in: Buletin of Geologic Sciences, No. 2/1982, Tirana.

Papa, A. "On some picularities of the relieve in flish territories", in: Geographic Studies, No. 2/1987, Tirana.

Qiriazi, P. (2006). Geography of Albania, Monography, Tirana.

Shallo, M., Gjata, Th., Vranai, A. "New concepts on the geology of EasterngAlbanides based on the example of the region Martanesh Cermenike - Klenje", in: Symposium of Studies, No. 2/1980, Tirana. 
